\author{
International Journal of Clinical Pharmacology \& Toxicology (IJCPT) \\ ISSN2167-910X
}

\title{
Simulated Evaluation of Drug-Impaired Psychomotor Performance
}

Research Article

Richmond $\mathrm{R}^{*}$

915 East Market Street, Box 12230, Searcy, AR, USA.

\begin{abstract}
The purpose of this placebo-controlled, randomized-crossover study was to evaluate a computer-based divided-attention task as a method for measure impaired human psychomotor performance. The ability of the divided-attention task to detect and differentiate was evaluated using single oral doses of placebo, caffeine and diphenhydramine. Ten healthy men were the subjects of the study. Subject performance on divided-attention was compared with tests of short-term memory and a set of visual analogue scales. The study also assessed potential learning and boredom effects associated with the testing procedures. The results indicate a divided-attention task can detect and differentiate effects of diphenhydramine from those of caffeine and placebo; however, it cannot differentiate effects of caffeine at the doses utilized from that of placebo. Visual analogue scale results corroborated these findings. Observations show that the short-term memory test was not sensitive to the effects of study medication. While the results observed with this convenient, computer-based divided-attention task are promising, additional studies need to be conducted with other classes of CNS-active drugs and over a range of doses.
\end{abstract}

Keywords: Psychomotor performance; Divided-attention; Short-term memory; Visual analogue scale; Diphenhydramine; Caffeine

\section{*CorrespondingAuthor:}

Richmond R,

915 East Market Street, Box 12230, Searcy, AR, USA.

Tel: 501-279-4858; Fax: 501-279-5202

E-mail: rrichmond@harding.edu

Received: June 27, 2014

Accepted: July 21, 2014

Published: July 23, 2014

Citation: Richmond R (2014) Simulated Evaluation of Drug-Impaired Psychomotor Performance. Int J Clin Pharmacol Toxicol. 3(2), 111-120. doi: http:/ / dx.doi.org/10.19070/2167-910X-1400021

Copyright: Richmond $\mathbf{R}^{\odot} 2014$ This is an open-access article distributed under the terms of the Creative Commons Attribution License, which permits unrestricted use, distribution and reproduction in any medium, provided the original author and source are credited.

\section{Introduction}

Many common side-effects associated with CNS-active drugs relate to the potential for impaired psychomotor performance. While frequently such effects (sedation, fatigue, etc.) may be transient and readily reversible, in more severe case can result in gross impairment of coordination, prolonged response time, and cognitive impairment.

Performance tasks have long been used to assess sensory, motor, and cognitive function under a variety of conditions. A number of techniques have been used to specifically determine the effects of drugs on these functions, however most measure only single performance variables. Although such tests may be valid and are often relied upon to indicate some degree of impairment or change in performance, they can be limited in their sensitivity and specificity [1].

Divided-attention tasks, which test multiple performance variables, provide an alternate means for testing both cognitive and sensorimotor impairment and may be more sensitive to drug effects when compared to single-variable performance tasks [2]. Some drugs used medicinally for which divided-attention tasks have been employed to evaluate side effects or adverse reactions include antihistamines [3-11], opioids [12-15], sedatives [16], stimulants [4,[17-19]] and psychotherapeutic agents [15,18,[2027]], among others [28-32]. However, their application with therapeutic drugs has been relatively limited and greater focus has been on validating their use in evaluating the effects of recreational drugs including alcohol [18,19,[24-27],[33-59]] marijuana $[36,52,55,56,[60-62]]$, and ecstasy [63].

The purpose of this study was to evaluate a computer-based divided-attention task as a method of objectively measuring the influence of centrally-active pharmacologic agents on human task performance. The study objectives were to: assess the ability of a divided-attention task to detect and differentiate the effects of a caffeine and diphenhydramine on human task performance; assess learning and boredom effects associated with the divided-attention task; and provide a basis for comparing the divided-attention task to other tests commonly used to measure drug-impaired performance.

\section{Materials and Methods}

Ten healthy, non-smoking, male subjects between 23-29 years of age (mean 25.5 years, \pm 2.0 ) participated in the study. Subjects' weights ranged between $60-90 \mathrm{~kg}$ (mean $76.0 \mathrm{~kg},+11.3$ ) and were within $15 \%$ of ideal body weight. Subjects had an average daily dietary intake of caffeine of $298 \mathrm{mg} /$ day and were excluded if they consumed $>325 \mathrm{mg} /$ day. Subjects were excluded from the study if they had a positive history of recreational drug abuse or consumed $>1$ ounce/day of alcohol (190 proof equivalent). Subjects were determined to qualify for the study after satisfactory completion of a medical interview and documentation of corrected vision of $20 / 30$ or better in both eyes. All subjects gave written informed consent and were paid for their participation. Prior to 
initiation, the study protocol was reviewed and approved by the Committee for Protection of the Rights of Human Subjects at the University of North Carolina at Chapel Hill.

A placebo-controlled, randomized, crossover study design was employed which included a training phase and four treatment phases. Each treatment phase consisted of a baseline period, a dosing period, and a washout period. During the baseline period subjects were queried regarding the use of any medication during the preceding 48 hours and the amount of sleep received the evening prior to the study to determine eligibility to participate in the study that day. During treatment phase 1 all subjects received placebo (PLA) in single-blind fashion. Treatment phases 2 through 4 were double-blind during which subjects received one of three oral treatments in random order including placebo (PLB), diphenhydramine $100 \mathrm{mg}$ (DPH), or caffeine 325mg (CAF). Subjects ingested study medication at $10 \mathrm{AM}$ (time 0 ) to avoid possible diurnal variation in performance.

Subjects received a caffeine-free snack and lunch at standard times during each treatment phase. Subjects were allowed to freely move about during the treatment phase but remained in the research unit until the current phase was completed. A washout period between treatments was established with a minimum of 18 hours and a maximum of 14 days.

A battery of three tests was used to measure task performance including a divided-attention task, a short-term memory test, and visual analogue scales.

\section{Divided-Attention Task (DAT)}

This computer-based test consisted of a central display monitor, two peripheral numeric displays, a four-button response panel, and a foot pedal (Figure 1). The central monitor, which graphically simulated a speedometer, and peripheral displays were arranged in a pattern similar to an automobile dashboard. The response panel in front of the subject was positioned midway between the peripheral displays, and the foot pedal was placed in a comfortable position on the floor. This test required the subject to monitor the central display, which presented digital numeric information changing approximately each 0.5 seconds, in the central field of vision. The subject was given a critical value range (53-57) for central display information to remember while performing the test. When the central display presented a number outside this critical range, the subject was instructed to respond by pressing the corresponding button on the response panel. Simultaneously, the peripheral displays presented a default value of 4 . If either the left or right display changed from the default value to the number 3 the subject pressed a corresponding left or right response button. If either display changed to the number 7 the subject pressed the foot pedal. If either display changed to the number 5 the subject was not to respond in any manner, the purpose of which was to measure false-positive responses. Subjects were tested for two 2-minute trials at each assessment time during which they received approximately 180 central and peripheral stimuli changes per trial. The inter-stimuli interval ranged from $0.23-0.75 \mathrm{sec}$. Alternate programs of stimuli were presented randomly during successive trials to minimize the likelihood that the sequences would be memorized.

DAT Score $=(\mathrm{C} \% /$ Clat $)+(\mathrm{PL} \% /$ PLlat $)+(\mathrm{PR} \% /$ PRlat $)+$ (F\%/Flat)

Scores were computed as the mean of the two trials at each assessment time using the above formula, where: $\mathrm{C} \%=$ percentage of correct responses to central display; Clat $=$ latency of responses (msec) to central display; $\mathrm{P} \%(\mathrm{~L}$ or $\mathrm{R})=$ percentage of correct responses to left or right peripheral displays corrected for falsepositive responses; and Plat $(\mathrm{L}$ or $\mathrm{R})=$ latency of responses to left or right peripheral displays; $\mathrm{F} \%=$ percentage of correct responses with the foot pedal; and Flat $=$ latency of foot pedal responses. A maximum score is not defined since theoretically scores could infinitely improve. However, the average scoring range is $5-40$.

\section{Short-Term Memory Test (STMT)}

During each assessment with this computer-based test, six sets of four related words were displayed on the screen at a rate of one word every two seconds; a sample list appears in Table 1. At the end of each presentation the subject typed the words back into the computer in order of sequence with correct spelling. Twentysix alternate word sets were presented randomly on successive trials to minimize memorization. Scores were computed according to the formula below, where: $\mathrm{W}=$ number of words remembered; $\mathrm{X}=$ number of words in correct sequence; $\mathrm{Y}=$ number of words misspelled; and $Z=$ number of words that did not appear in the presentation. The maximum score attainable on this test is $100 \%$.

STMT Score $=[(\mathrm{W}+\mathrm{X}-1 / 2 \mathrm{Y}-\mathrm{Z}) * 100] / 48$

Figure 1. Graphical Representation of Computerized Divided-Attention Task

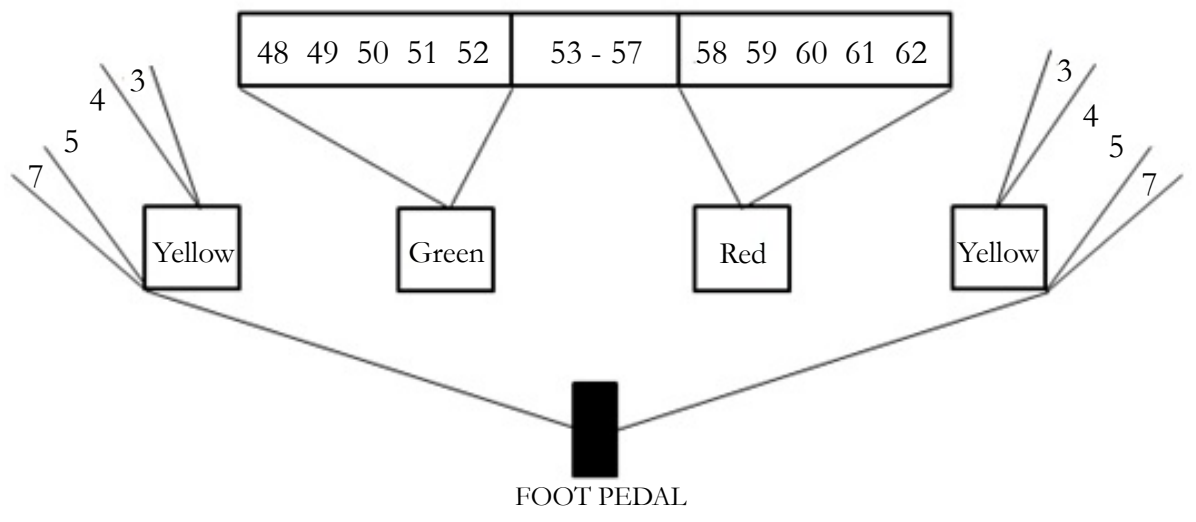


Table 1. SampleShort-TermMemoryTest

\begin{tabular}{|cccccc|}
\hline FRANCE & BROWN & CARROT & CROW & HAMMER & ROSE \\
ITALY & MAROON & POTATO & WREN & CHISEL & TULIP \\
SWEDEN & AQUA & CELERY & DOVE & SCREW & LILY \\
NORWAY & BURGUNDY & CABBAGE & PENGUIN & SANDPAPER & DAISY \\
\hline
\end{tabular}

\section{Visual Analogue Scales (VAS)}

Subjects were asked to express their perceived present physical and emotional state by drawing a perpendicular mark across a set of 18 ungraduated $100 \mathrm{~mm}$ lines (Figure 2). At opposing ends of each were pairs of contrasting adjectives and the line represented the entire spectrum between the adjectives with the extreme ends expressing absolute, and somewhere in between corresponding to how the subject would normally feel [64]. VAS scores were determined by measuring from the middle of the line to the subject's mark and reported as + depending on whether the adjective closest the mark was a positive or negative response. The score at each assessment time is reported as a mean of all 18 individual line scores. The "interested-bored" continuum, a single line of the full VAS test, was used to directly measure boredom. A training phase was conducted to instruct individual subjects on how to perform each task the day before study commencement. Training consisted of 30 trials on the DAT in order to provide sufficient practice time to reach a performance plateau with a reference score being established using the mean of the last 20 performance trials. A single trial with the STMT and VAS tasks served as training for those test procedures. During each baseline period subjects completed two DAT trials with the mean of these DAT scores being recorded as the baseline score for that treatment phase. They also completed a STMT and VAS trial to establish a baseline score. During treatment phase 1 the subjects were tested using only DAT. The purpose of this phase was to allow observation of subject performance on DAT without interaction of the other performance tests while under normal test conditions. During treatment phases 2 through 4, subjects were

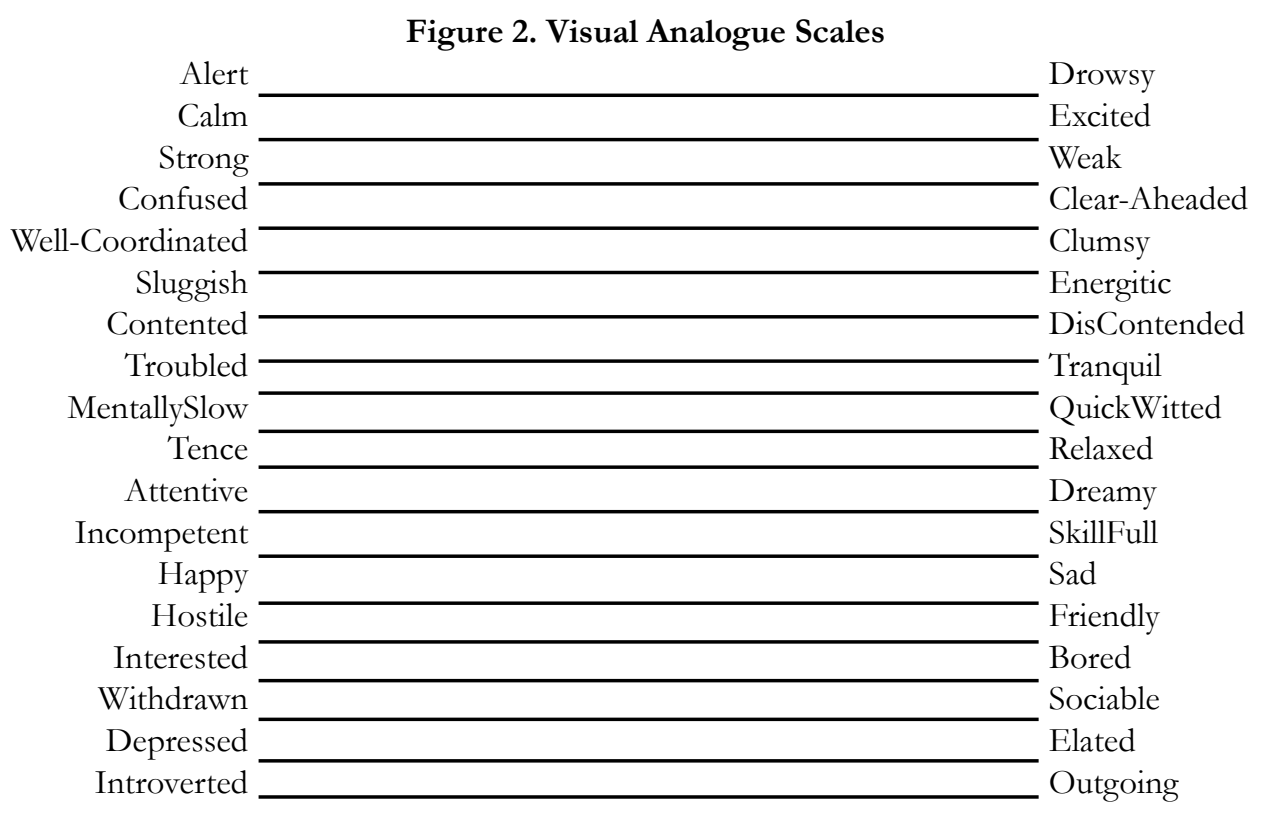

Table 2. Divided-Attention Performance Task Scores (Mean+SD)

\begin{tabular}{|l|c|c|c|c|c|c|c|c|c|c|c|c|}
\hline & \multicolumn{10}{|c|}{ TIME(mins) } \\
\hline TREATMENT & $\mathbf{0}$ & $\mathbf{3 0}$ & $\mathbf{5 0}$ & $\mathbf{7 0}$ & $\mathbf{9 0}$ & $\mathbf{1 2 0}$ & $\mathbf{1 5 0}$ & $\mathbf{1 8 0}$ & $\mathbf{2 1 0}$ & $\mathbf{2 4 0}$ & $\mathbf{2 7 0}$ & $\mathbf{3 0 0}$ \\
\hline PLA & 24.9 & 22.8 & 22.7 & 23.1 & 24.4 & 24 & 23.4 & 23.7 & 22.9 & 24.1 & 23.6 & 22.9 \\
\hline Mean+SD & 2.4 & 2.9 & 3.9 & 2.4 & 3.3 & 3.1 & 4 & 2.7 & 4.7 & 3.7 & 2.9 & 1.6 \\
\hline PLB & 25.5 & 24.1 & 26.3 & 24.3 & 25 & 25.2 & 26.7 & 25.9 & 24.7 & 25.7 & 22.9 & 24 \\
\hline Mean+SD & 2.4 & 2.8 & 3.8 & 2.7 & 4.2 & 3 & 3.5 & 3.9 & 3.5 & 2.9 & 3.1 & 7.1 \\
\hline CAF & 25.6 & 26.1 & 26.3 & 25.4 & 26.8 & 27.1 & 26.8 & 26.1 & 27.3 & 26.3 & 26 & 26 \\
\hline Mean+SD & 3.2 & 2.9 & 2.8 & 3.1 & 3.6 & 1.8 & 3.9 & 3.2 & 2.4 & 3.9 & 2.2 & 3.9 \\
\hline DPH & 25.9 & 26.2 & 25.8 & 23.5 & 21.8 & 21.2 & 21.3 & 19.4 & 18.8 & 22.3 & 23.4 & 23.1 \\
\hline Mean+SD & 2.1 & 2.6 & 3.9 & 2.9 & 2.6 & 3.3 & 4.3 & 6.3 & 3 & 2.5 & 4.1 & 5.6 \\
\hline
\end{tabular}

PLA (Placebo A; Treatment Phase 1), PLB (Placebo, Treatment Phases 2-4), CAF (Caffeine 325mg), DPH (Diphenhydramine 100mg), SD (standard deviation) 
tested using all three tasks following the order of DAT, STMT and VAS. DAT and STMT testing was performed during all treatment phases at 30, 50, 70, 90, 120, 150, 180, 210, 240, 270 and 300 mins following drug administration, while VAS testing was performed at essentially hourly at 70, 120, 180, 240 and 300 mins.

\section{Data Analysis}

The ability of the tests to detect drug effect on task performance was assessed using the pharmacodynamic parameters of maximum change in score from baseline and time of maximum change. To determine whether the tests could differentiate between the effect of CAF, DPH and PLB, data was summarized at individual time points for each performance test using the mean + standard deviation. Treatment differences were evaluated for each test at individual time points with repeated measures analysis of variance (ANOVA) for a three period crossover study. The ANOVA model included the predictor variables subject, phase and treatment. Type III sum of squares was used to simultaneously control for all main effects in the model at the same time. The level of significance $(\alpha)$ for differences in main effect was 0.05 . Three pairwise treatment comparisons were also performed with the level of significance adjusted for multiple comparisons, controlling for type I error, to a value of $0.05 / 3$ (0.017). Learning effects associated with DAT were evaluated at individual time points using the phase predictor variable from the ANOVA model. Boredom effects associated with the testing procedures were assessed subjectively using the "interested-bored" continuum of the VAS test. Carryover effect was evaluated by adding prior treatment as a predictor variable to the ANOVA model in addition to subject, phase and treatment. The results obtained with DAT at each time interval were compared with those obtained with STMT and VAS using a nonparametric test of correlation (Spearman's Rank Correlation Coefficient).

\section{Results}

Performance on Divided-Attention Task
DAT scores across treatment phases and times and are summarized in Table 2 and represented in Figures 3 and 4. During PLA, PLB and CAF treatment phases no discernible pattern of alteration in DAT scores was observed. Following DPH treatment DAT scores remained essentially unchanged during the first three time intervals, but then performance declined to a mean maximum change in DAT score of -7.1 at 210 minutes and did not return to baseline. There was a slow-down in the decline of performance at 150 mins which followed the scheduled caffeinefree snack at 120 minutes. Pairwise comparisons of DAT scores summarized in Table 3 reveal a statistically significant treatment effect between PLB and DPH during the period of 120 to 210 mins, and CAF and DPH during the period of 90 to 210 mins. No statistical differences in DAT scores between PLB and CAF treatment were noted. Carryover effect influencing DAT performance was not evident at any time $(p=0.10)$.

DAT scores during the training phase are represented in Figure 5. Subjects began the training phase with a mean group DAT score of $9.9+3.1$ (Range, 5.1-14.4). The group reference score established as a mean of trials 21-30 was $22.4+2.4$ (Range, 18.9-26.5).

Subjects demonstrated a clinically significant learning effect on successive trials that eventually appeared to plateau by the end of the training phase. However, when the DAT reference score is compared to baseline DAT scores observed over successive treatment phases, a continued numerical increase can be observed (Figure 6) with DAT scores incrementally increasing by $19.2 \%$ from the training phase to the baseline of treatment phase 3. A review of individual scores reveals that four subjects continued to improve across the entire study with peak baseline performance being observed at the beginning of treatment phase 4; five subjects had peak baseline performance in treatment phase 3 with subsequent decay in treatment phase 4 ; and one subject had peak performance in treatment phase 2 with decay in both successive treatment phases. In the majority of cases, the most substantial improvement was observed between the training phase and the first treatment phase. A statistically significant phase effect of DAT scores was observed at 30 mins $(p<0.0088)$ indicating additional learning effect or potential motivation.

Figure 3. Divided-Attention Scores on PLA (Placebo) during Treatment Phase 1

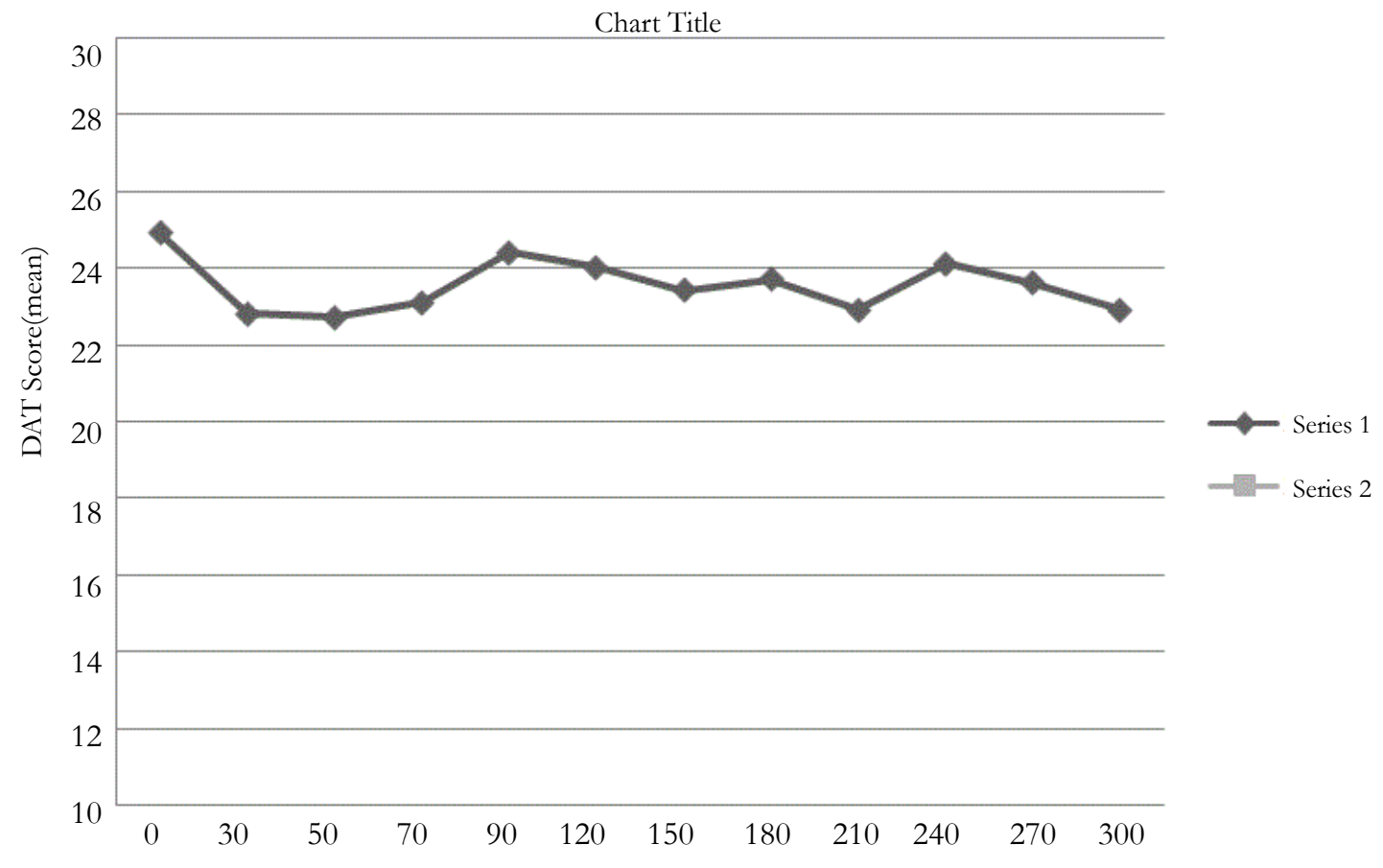


Figure 4:Divided-Attention Task Performance Scores on PLB (Placebo), CAF (Caffeine 325mg) and DPH (Diphenhydramine 100mg) Treatments during Treatment Phases 2-4

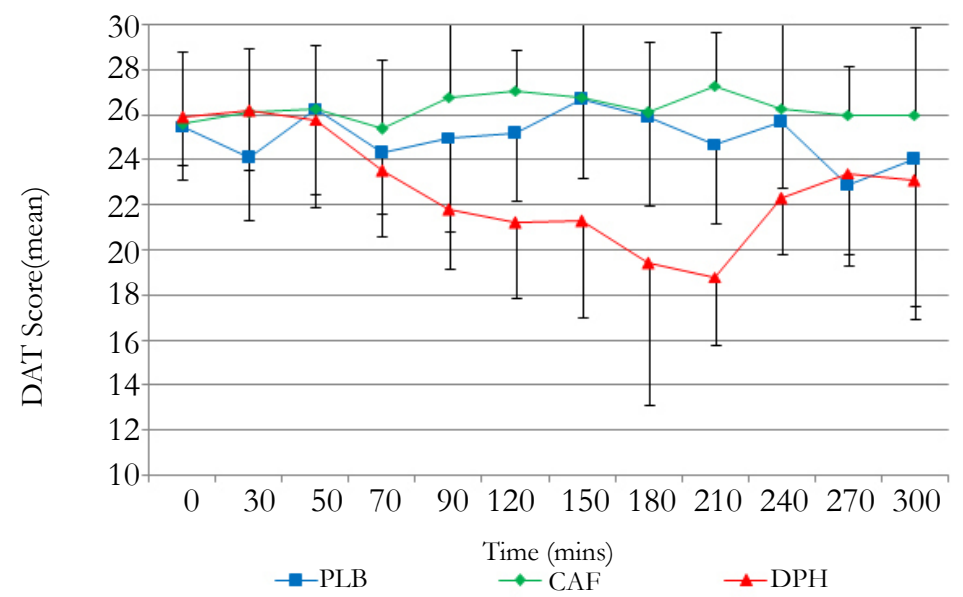

Table 3. Pairwise Comparisons of Task Performance Scores

\begin{tabular}{|c|c|c|c|c|c|c|c|c|c|c|c|c|}
\hline & \multicolumn{10}{|c|}{ TIME (mins) } \\
\hline TASK & $\mathbf{0}$ & $\mathbf{3 0}$ & $\mathbf{5 0}$ & $\mathbf{7 0}$ & $\mathbf{9 0}$ & $\mathbf{1 2 0}$ & $\mathbf{1 5 0}$ & $\mathbf{1 8 0}$ & $\mathbf{2 1 0}$ & $\mathbf{2 4 0}$ & $\mathbf{2 7 0}$ & $\mathbf{3 0 0}$ \\
\hline \multicolumn{10}{|c|}{ PLB vs. DPH } \\
\hline DAT & NS & NS & NS & NS & NS & 0.002 & 0.003 & 0.005 & 0.000 & NS & NS & NS \\
\hline VAS & NS & - & - & 0.007 & - & 0.000 & - & 0.000 & - & 0.001 & - & NS \\
\hline STMT & NS & NS & NS & NS & NS & NS & NS & NS & NS & NS & NS & NS \\
\hline \multicolumn{10}{|c|}{ CAF vs. DPH } \\
\hline DAT & NS & NS & NS & NS & 0.005 & 0.000 & 0.007 & 0.005 & 0.000 & NS & NS & NS \\
\hline VAS & NS & - & - & NS & - & 0.000 & - & 0.000 & - & 0.001 & - & NS \\
\hline STMT & NS & NS & NS & NS & NS & NS & NS & NS & NS & NS & NS & NS \\
\hline \multicolumn{10}{|c|}{ PLB vs. CAF } & \multicolumn{7}{|c|c|c|}{} \\
\hline DAT & NS & NS & NS & NS & NS & NS & NS & NS & NS & NS & NS & NS \\
\hline VAS & NS & - & - & NS & - & NS & - & NS & - & NS & - & NS \\
\hline STMT & NS & NS & NS & NS & NS & NS & NS & NS & NS & NS & NS & NS \\
\hline
\end{tabular}

PLB (Placebo, Treatment Phases 2-4), DPH (Diphenhydramine 100mg), CAF (Caffeine 325mg), DAT (Divided-attention task), VAS (Visual analogue scales), STMT (Short-term memory test), NS (non-significant)

Figure 5. Learning Effect Observed during Pre-Study Divided-Attention Task Training

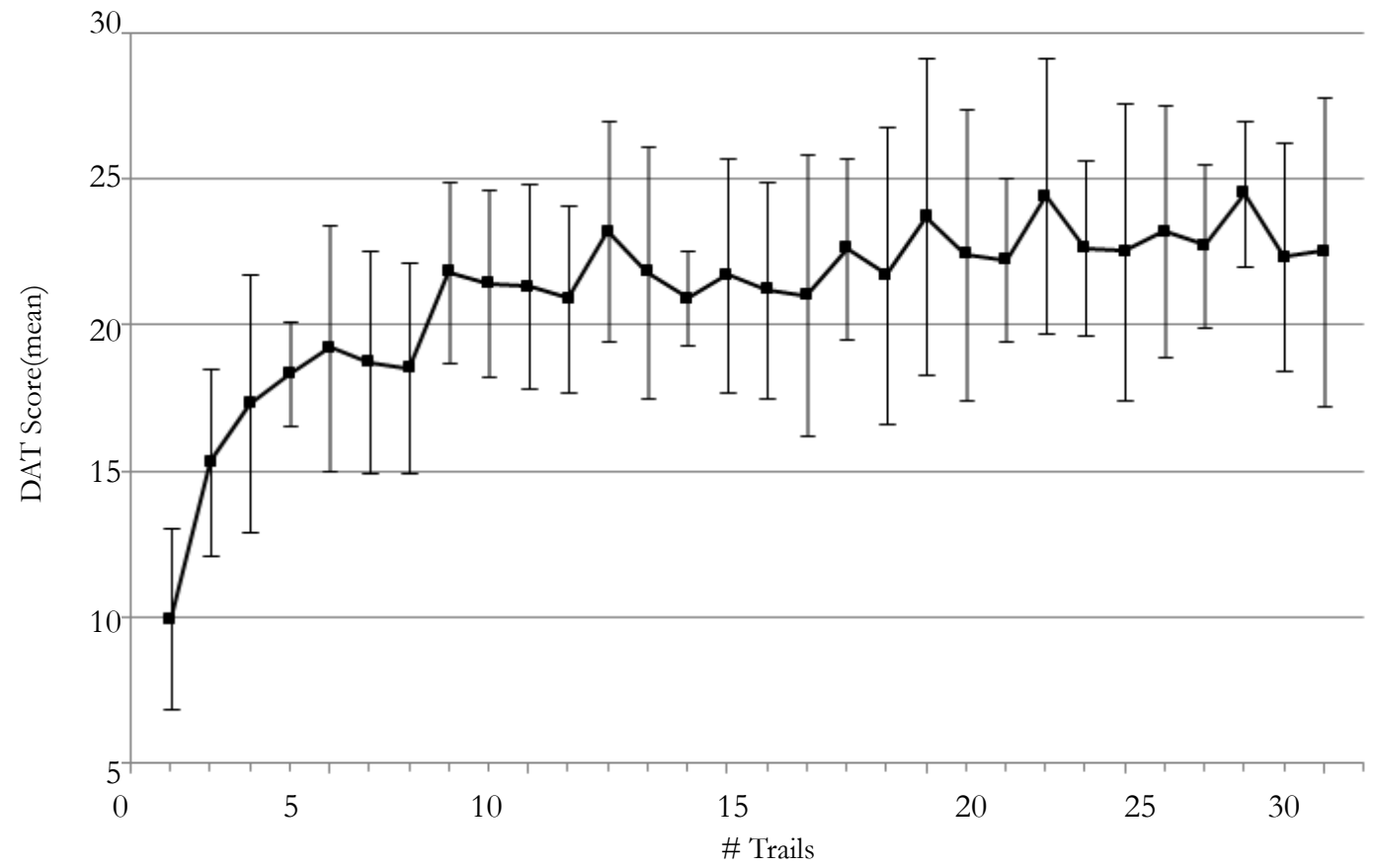


Figure 6. Evaluation of Continued Learning Effect on the Divided-Attention Task when the Training Phase Reference Score is Compared to Baseline Scores during Treatment Phases 1-4

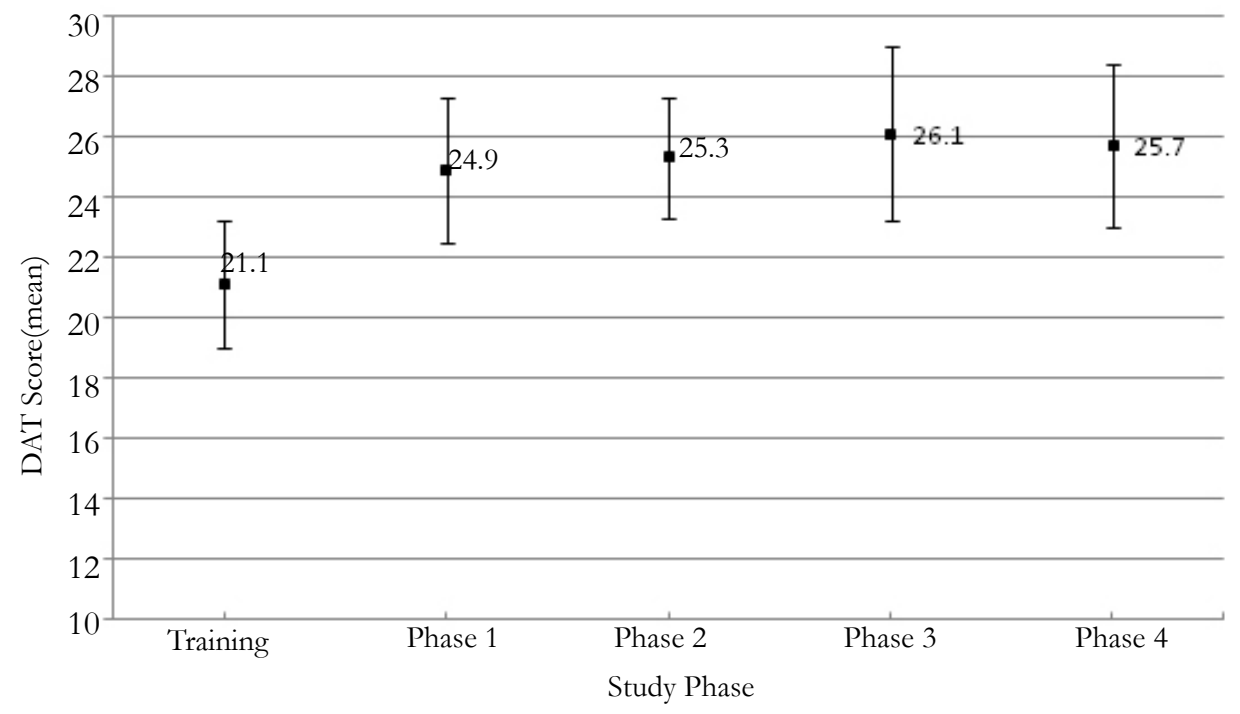

\section{Performance on Visual Analogue Scales}

VAS scores across treatment phases and times and are summarized in Table 4 and represented in Figure 7. A maximum change in VAS score from baseline was observed at 180 mins during DPH treatment and, similar to DAT, scores did not return to baseline. Pairwise comparisons of VAS scores summarized in Table 3 reveal a statistically significant treatment effect between PLB and DPH during the period of 70 to 240 mins, and between CAF and DPH during the period of 120 to 240 mins. VAS scores exhibited no change from baseline during PLB and CAF treatments. Carryover effect influencing VAS performance was not evident at any time $(p=0.2468)$. As assessment of boredom, using the "interested-bored" continuum as a single-line component of the full VAS test, revealed a slight but clinically and statistically insignificant increase in mean boredom score from baseline to 300 mins during each treatment. However, considerable inter-subject variability was also evident.

\section{Performance on Short-Term Memory Test}

STMT scores across treatment phases and times and are summarized in Table 5 and represented in Figure 8. STMT scores were numerically higher after CAF and numerically lower after DPH. However, scores remained more uniform across treatments when compared to DAT or VAS scores with no statistical differences in STMT scores being detected during any treatment.

\section{CorrelationbetweenPerformance'Tasks}

During DPH treatment, a comparison of DAT performance with that of VAS revealed an inverse correlation $(r=-0.32 ; \mathrm{p}<0.01)$. The observed negative correlation was consistent with the scoring process used in the two tests, with a decrease in DAT score and an increase in VAS score both reflecting a decrease in performance. Likewise, during DPH treatment, a comparison of DAT performance with that of STMT revealed a statistically significant correlation $(\mathrm{r}=0.33$; $\mathrm{p}<0.003)$. During either PLB or CAF treatments no correlation was observed between DAT and VAS or STMT performance.

\section{Discussion}

The primary objectives of the investigation were to validate the ability of a divided-attention task to detect (demonstrate sensitivity) and differentiate (demonstrate specificity) the effects of placebo, diphenhydramine and caffeine on psychomotor performance, and to compare divided-attention task scores with those obtained with other tests that are commonly used to detect drug-induced changes in performance.

The results show that DAT demonstrated the sensitivity needed to detect the depressant effects of DPH. The change in DAT scores appeared to inversely approximate the previously report-

Table 4. Visual Analogue Scale Performance Task Scores (Mean + SD)

\begin{tabular}{|l|l|l|l|l|l|l|}
\hline & \multicolumn{7}{|c|}{ TIME (mins) } \\
\hline TREATMENT & 0 & 70 & 120 & 180 & 240 & 300 \\
\hline PLB & 32.4 & 30 & 29.3 & 29.6 & 31.1 & 30.6 \\
\hline Mean + SD & 9.8 & 11.2 & 8.2 & 9.4 & 10.8 & 11.1 \\
\hline CAF & 30.7 & 29.2 & 28.6 & 28.3 & 29.5 & 27.1 \\
\hline Mean + SD & 11.9 & 11.8 & 11 & 10 & 10 & 10.8 \\
\hline DPH & 36.4 & 41.1 & 54 & 56 & 45.3 & 38.5 \\
\hline Mean + SD & 13.6 & 14.3 & 14 & 13 & 12.5 & 15.9 \\
\hline
\end{tabular}

PLB (Placebo, Treatment Phases 2-4), CAF (Caffeine 325mg), DPH (Diphenhydramine 100mg), SD (standard deviation) 
Figure 7. Visual Analogue Scale Performance Scores on PLB (Placebo), CAF (Caffeine 325mg) and DPH (Diphenhydramine 100mg) Treatments during Treatment Phases 2-4

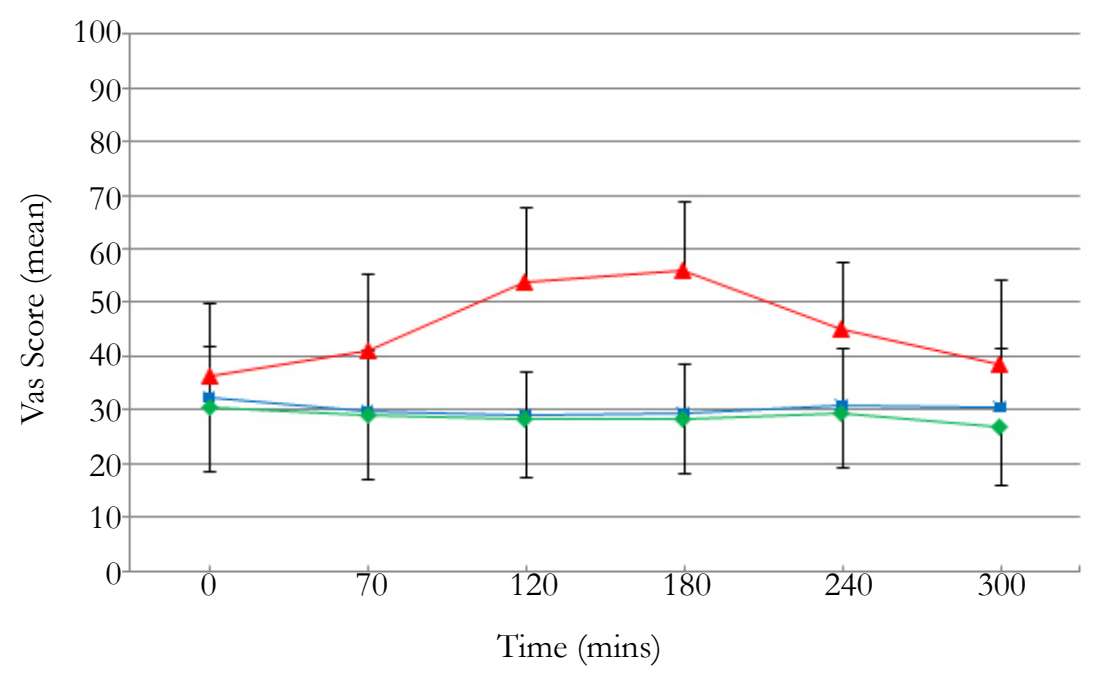

ed serum concentration-time curve observed after a single, oral dose of diphenhydramine $100 \mathrm{mg}$ [65]. Additionally, the time interval between DPH administration and maximum decrease in DAT performance at 210 mins corresponds well with the time at which peak sedative effects are reported to occur following oral diphenhydramine administration (120-240 mins) [66]. Not only was there an apparent dose-response effect with DAT scores, but a time interaction was also evident which corresponded to the scheduled administration of a snack provided following assessments at 120 mins. The subsequent delay of decline in performance noted at 150 mins would suggest that the snack provided sufficient stimulus to arouse the subjects. Further, the observed sensitivity of DAT to depressant effects is consistent with results obtained in other studies using the same DAT apparatus where CNS depressant effects have been characterized for ethanol [19,[56-59]], and marijuana [56]. These results are corroborated by VAS scores where the subjects subjectively rated themselves as impaired. These results are also consistent with previous studies involving diphenhydramine $[65,67,68]$. DAT also appears to be associated with a degree of specificity for DPH effect because the performance curves obtained with DPH and CAF, when compared, are both visibly and statistically different.

While the depressant effects of DPH on DAT performance were demonstrable, sensitivity to the stimulant effects of CAF was not evident. Peak stimulant effects following a single oral dose of caffeine are reported to occur at approximately 60 mins [69]. However, the DAT performance curve obtained following treatment with CAF cannot be characterized as being different from that observed after PLB administration. These results are similar to those observed with VAS, which also displayed no significant difference in influence of CAF and PLB treatments. The lack of sensitivity for stimulant effects are in contrast to previous results which showed that decrements in the accuracy and latency of response produced by ethanol were significantly attenuated by dextroamphetamine in a dose-response fashion [19]. The contrasting results may be a reflection of study design, because in the present study each agent was singularly administered and the interaction

Figure 8. Short-Term Memory Test Performance Scores on PLB (Placebo), CAF (Caffeine 325mg) and DPH (Diphenhydramine 100mg) Treatments during Treatment Phases 2-4

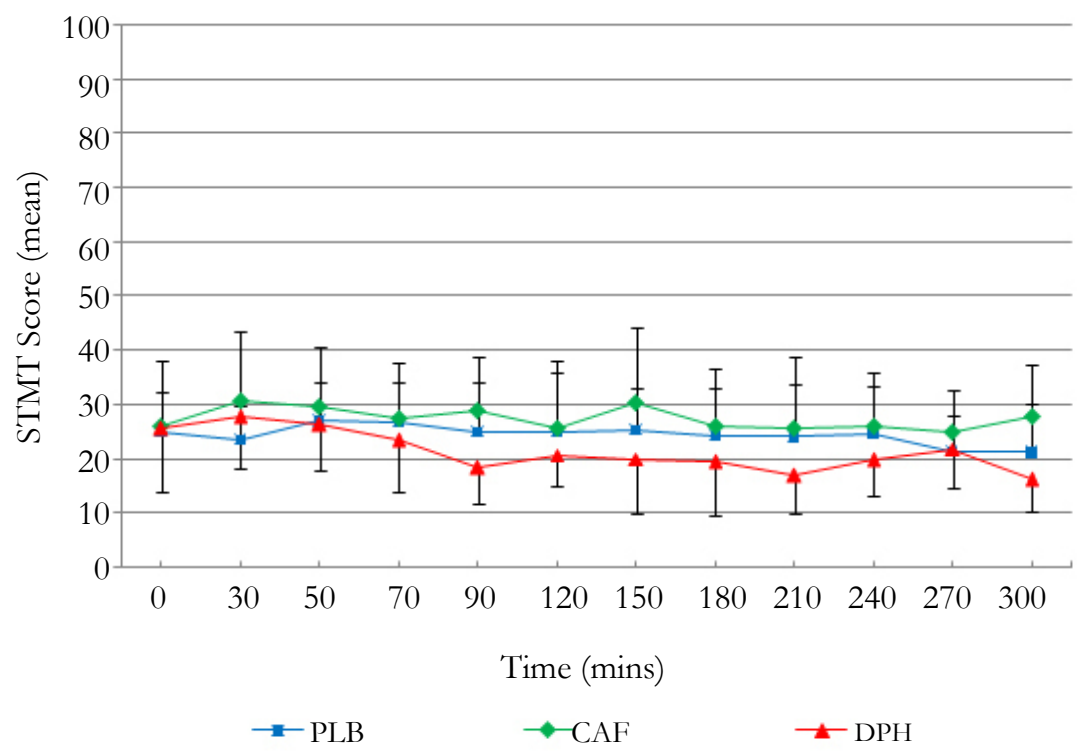


Table 5. Short-Term Memory Test Performance Task Scores (Mean + SD)

\begin{tabular}{|l|l|l|l|l|l|l|l|l|l|l|l|l|}
\hline & \multicolumn{10}{|c|}{ TIME (mins) } \\
\hline TREATMENT & 0 & 30 & 50 & 70 & 90 & 120 & 150 & 180 & 210 & 240 & 270 & 300 \\
\hline PLB & 25.1 & 23.5 & 27 & 26.9 & 24.9 & 24.9 & 25.4 & 24.3 & 24.1 & 24.6 & 21.4 & 21.2 \\
\hline Mean + SD & 7.1 & 6.4 & 7.2 & 7.2 & 9.1 & 11 & 7.6 & 8.9 & 9.7 & 8.9 & 6.5 & 8.9 \\
\hline CAF & 26 & 30.7 & 29.7 & 27.6 & 29 & 25.5 & 30.5 & 26.1 & 25.5 & 26.1 & 25.1 & 27.8 \\
\hline Mean + SD & 12 & 13 & 11 & 10.1 & 10 & 12.6 & 13.9 & 10.6 & 13.5 & 9.7 & 7.8 & 9.6 \\
\hline DPH & 25.5 & 27.7 & 26.4 & 23.5 & 18.5 & 20.7 & 20 & 19.4 & 16.9 & 19.8 & 21.8 & 16.2 \\
\hline Mean + SD & 11.7 & 9.6 & 8.4 & 9.4 & 6.7 & 5.8 & 10 & 9.7 & 6.9 & 6.7 & 7.3 & 5.8 \\
\hline
\end{tabular}

PLB (Placebo, Treatment Phases 2-4), CAF (Caffeine 325mg), DPH (Diphenhydramine 100mg), SD (standard deviation)

between sedative and stimulant agents was not assessed.

Alternatively, the lack of a significant stimulant effect due to CAF administration as compared to the magnitude of the depressant effect noted following DPH treatment may be explained by differences in the magnitude of doses of the study drugs or caffeine tolerance. The intent in this study was to give a sufficient dose of each drug to insure the presence of a measurable response. Although the CNS effect of DPH is well known it is difficult to find reports of objectively measured sedation at recommended adult doses, and individual variability in response to the sedative effects of DPH precludes accurate prediction of side-effect potential as $50 \%$ of the recipients of DPH in usual adult doses do not experience significant sedation [65].Because of this variability and because of the small number of subjects enrolled in the study, a dose twice the maximum recommended adult dose was used. By comparison, $325 \mathrm{mg}$ of caffeine is approximately equivalent to only two cups of brewed coffee. Even though the study controlled for methylxanthine use, because subjects ingested some amount of caffeine on a daily basis a degree of tolerance was inherently present among subjects. A statistically detectable change in performance due to CAF may have been produced had the dose been proportionally higher or if a larger number of subjects had been enrolled. Finally, although increases in alertness and improvement in performance have been reported, negative results are also reported in the literature from studies in which caffeine has exhibited no effect on cognition and learning and has impaired fine motor coordination [69-72].

While both DAT and VAS were sensitive to and were demonstrated to correlate during DPH treatment, STMT was not affected by any of the drugs. These findings also contrast with previous studies involving use of short-term memory tests [1]. However, given the level of memory being tested, the manner in which the test was administered, and some problems that were noted with external disruption, word-list repetition, and complex scoring procedure, these results are not surprising. These limitations are consistent with previous reports that have utilized short-term memory tasks as performance testing tools.

The DAT testing procedure was noted to have significant learning effect as is common with tasks involving sensorimotor coordination. However, intensive training methods that were used to minimize these effects appeared to be effective based on the plateau in DAT scores achieved during the training phase. Nonetheless, an analysis of baseline scores across successive treatment phases appeared to reveal a continued slight learning effect. Within treatment phase assessment of learning was statistically significant at only one assessment time (30 mins).

When boredom was assessed utilizing the "interested-bored" continuum of VAS, boredom ratings increased from baseline to 300 mins during all treatments although this change was not statistically significant. Clinically, the curves for each treatment are indistinguishable, with a trend toward greater boredom during the DPH phase. By comparison, an analysis of scores obtained during treatment phase 1 when DAT was the only testing procedure employed reveals an immediate decrease in scores from baseline at 30 mins which was sustained for the remainder of the phase. This is in contrast to the more variable DAT score obtained during PLB phase, during which all three tests were performed. Although it is difficult to determine the cause of this phenomenon, it would appear that sufficient performance demand was not placed on the subjects, perhaps representing boredom.

A number of characteristics have been described for an ideal testing procedure that would reliably evaluate the effects of a CNSactive drug on psychomotor performance. The task would allow for standardized test conditions, be designed for rapid administration, require minimal training of test administrators, not exhibit strong practice or fatigue effects during repeated administration, be sensitive and specific to various pharmacologic agents across a range of doses, correlate well with other test procedures, allow for efficient data acquisition, storage and analysis, be portable to facilitate use in field studies, and have high subject acceptance and be amenable for application to a wide variety of subject populations[73].

A limitation noted with the study design is that the subject population selected may not be representative of the population who most frequently uses the studied medications. The small sample size used in this study required that a homogeneous population be selected and attempts were made to control a number of subjectspecific sources of variability previously identified in the literature. These included age due to reports of drug-induced changes in performance being more profound with increasing age $[74,75]$, gender [75-77], and weight to reduce variability in response to administration of a fixed-dose of a drug.

\section{Conclusions}

The results of this study indicate that a divided-attention task is sensitive to the CNS depressant effects of diphenhydramine, and can differentiate those effects from the stimulant effects of caffeine as well as placebo. The correlation observed between the divided-attention task and visual analogue scales in subjects receiving diphenhydramine provides evidence that this battery of tests may be complimentary and reliable as a measure of CNS depressant effects with other CNS active drugs. The lack of correlation between these tasks in subjects taking caffeine probably reflects an absence of measurable effect and more studies need to be done 
to validate their use with stimulants. Leaning effect can be effectively managed with the divided-attention task as long as effective training is employed, and the testing procedure does not appear to be affected by or induce feelings of boredom over repeated measures. Divided-attention tasks therefore effectively meet many of the criteria desirable in a performance evaluation system, measuring skills of attention, memory, recognition, decision making, and reaction time. While the results seen with this conveniently administered computer-based task are promising, additional studies examining the ability of DAT to detect drug-induced changes of performance need to be conducted, and should include other classes of centrally-active drugs over a range of doses.

\section{Acknowledgements}

The author would like to thank and acknowledge Samantha Morrison and Nicole Michael for assistance in preparing this manuscript.

\section{Conflict of Interest}

The author declares no conflict of interest.

\section{References}

[1]. Hindmarch I.(1980) Psychomotor function and psychoactive drugs. Br J Clin Pharmacol 10:189-209.

[2]. Moskowitz H. (1984) Attention tasks as skills performance measures of drug effects. Br J Clin Pharmacol 18: 51S-61S.

[3]. Conen S, Theunissen EL, Vermeeren A, Ramaekers JG (2011) Short-term effects of morning versus evening dose of hydroxyzine $50 \mathrm{mg}$ on cognition in healthy volunteers. J Clin Psychopharmacol 31(3): 294-301.

[4]. Theunissen EL, Elvira Jde L, van den Bergh D, Ramaekers JG (2009) Comparing the stimulant effects of the $\mathrm{H} 1$-antagonist fexofenadine with 2 psychostimulants, modafinil and methylphenidate. J Clin Psychopharmacol 29(5): 439-43.

[5]. Theunissen EL, Vermeeren A, Ramaekers JG (2006) Repeated-dose effects of mequitazine, cetirizine and dexchlorpheniramine on driving and psychomotor performance. Br J Clin Pharmacol 61(1): 79-86

[6]. Theunissen EL, Jonkman LM, Kuypers KP, Ramaekers JG (2006) A combined neurophysiological and behavioural study into the stimulating effects of fexofenadine on performance. J Psychopharmacol 20(4): 496-505

[7]. Theunissen EL, Vermeeren A, van Oers AC, van Maris I, Ramaekers JG (2004) A dose-ranging study of the effects of mequitazine on actual driving, memory and psychomotor performance as compared to dexchlorpheniramine, cetirizine and placebo. Clin Exp Allergy 34(2): 250-8

[8]. Kay GG, Harris AG (1999) Loratadine: a non-sedating antihistamine. Review of its effects on cognition, psychomotor performance, mood and sedation. Clin Exp Allergy 29(3): 147-50.

[9]. Vuurman EF, Uiterwijk MM, Rosenzweig P, O'Hanlon JF (1994) Effects of mizolastine and clemastine on actual driving and psychomotor performance in healthy volunteers. Eur J Clin Pharmacol 47(3): 253-9.

[10]. Witek TJ Jr, Canestrari DA, Miller RD, Yang JY, Riker DK (1992) The effects of phenindamine tartrate on sleepiness and psychomotor performance. J Allergy Clin Immunol 90(6 Pt 1): 953-61.

[11]. Burns M, Moskowitz H (1980) Effects of diphenhydramine and alcohol on skills performance. Eur J Clin Pharmacol 17(4): 259-66.

[12]. Mailis-Gagnon A, Lakha SF, Furlan A, Nicholson K, Yegneswaran B, et al. (2012) Systematic review of the quality and generalizability of studies on the effects of opioids on driving and cognitive/psychomotor performance. Clin J Pain 28(6): 542-55.

[13]. Schoedel KA, McMorn S, Chakraborty B, Zerbe K, Sellers EM (2010) Reduced cognitive and psychomotor impairment with extended-release oxymorphone versus controlled-release oxycodone. Pain Physician 13(6): 56173.

[14]. Mintzer MZ, Lanier RK, Lofwall MR, Bigelow GE, Strain EC (2010) Effects of repeated tramadol and morphine administration on psychomotor and cognitive performance in opioid-dependent volunteers. Drug Alcohol Depend 111(3): 265-8.

[15]. Lichtor JL, Alessi R, Lane BS. (2002) Sleep tendency as a measure of recovery after drugs used for ambulatory surgery. Anesthesiology 96(4): 878-83.

[16]. Wilkinson CJ (1995) The acute effects of zolpidem, administered alone and with alcohol, on cognitive and psychomotor function. J Clin Psychiatry
56(7): 309-18.

[17]. Mills KC, Spruill SE, Kanne RW, Parkman KM, Zhang Y (2001) The influence of stimulants, sedatives, and fatigue on tunnel vision: risk factors for driving and piloting. Hum Factors 43(2): 310-27.

[18]. Liguori A, Robinson JH (2001) Caffeine antagonism of alcohol-induced driving impairment. Drug Alcohol Depend 63(2): 123-9.

[19]. Perez-Reyes M, White WR, McDonald SA, Hicks RE (1992) Interaction between ethanol and dextroamphetamine: effects on psychomotor performance. Alcohol Clin Exp Res 16(1): 75-81.

[20]. Troost PW, Althaus M, Lahuis BE, Buitelaar JK, Minderaa RB, et al. (2006) Neuropsychological effects of risperidone in children with pervasive developmental disorders: a blinded discontinuation study. J Child Adolesc Psychopharmacol 16(5): 561-73.

[21]. Hindmarch I, Trick L, Ridout F (2005) A double-blind, placebo- and positive-internal-controlled (alprazolam) investigation of the cognitive and psychomotor profile of pregabalin in healthy volunteers. Psychopharmacology (Berl) 183(2): 133-43.

[22]. van Laar MW, Volkerts ER, Verbaten MN, Trooster S, van Megen HJ, et al. (2002) Differential effects of amitriptyline, nefazodone and paroxetine on performance and brain indices of visual selective attention and working memory. Psychopharmacology (Berl) 162(4): 351-63.

[23]. O'Hanlon JF, Robbe HW, Vermeeren A, van Leeuwen C, Danjou PE (1998) Venlafaxine's effects on healthy volunteers' driving, psychomotor, and vigilance performance during 15-day fixed and incremental dosing regimens. J Clin Psychopharmacol 18(3): 212-21.

[24]. Linnoila M, Erwin CW, Brendle A, Logue P (1981) Effects of alcohol and flunitrazepam on mood and performance in healthy young men. J Clin Pharmacol 21(10): 430-5.

[25]. Saario I (1976) Psychomotor skills during subacute treatment with thioridazine and bromazepam and their combined effects with alcohol. Ann Clin Res 8(2): 117-23.

[26]. Palva ES, Linnoila M, Mattila MJ (1976) Effect of active metabolites of chlordiazepoxide and diazepam, alone or in combination with alcohol, on psychomotor skills related to driving. Mod Probl Pharmacopsychiatry 11: 79-84

[27]. Seppälä T, Saario I, Mattila MJ (1976) Two weeks' treatment with chlorpromazine, thioridazine, sulpiride, or bromazepam: actions and interactions with alcohol on psychomotor skills related to driving. Mod Probl Pharmacopsychiatry 11: 85-90

[28]. Atzori G, Lemmonds CA, Kotler ML, Durcan MJ, Boyle J (2008) Efficacy of a nicotine $(4 \mathrm{mg})$-containing lozenge on the cognitive impairment of nicotine withdrawal. J Clin Psychopharmacol 28(6): 667-74.

[29]. Kurzthaler I, Bodner T, Kemmler G, Entner T, Wissel J (2005) The effect of nabilone on neuropsychological functions related to driving ability: an extended case series. Hum Psychopharmacol 20(4): 291-3.

[30]. Delcker A, Wilhelm H, Timmann D, Diener HC (1997) Side effects from increased doses of carbamazepine on neuropsychological and posturographic parameters of humans. Eur Neuropsychopharmacol 7(3): 213-8.

[31]. Brouwers P, Hendricks M, Lietzau JA, Pluda JM, Mitsuya H (1997) Effect of combination therapy with zidovudine and didanosine on neuropsychological functioning in patients with symptomatic HIV disease: a comparison of simultaneous and alternating regimens. AIDS 11(1): 59-66.

[32]. Roth T, Richardson GR, Sullivan JP, Lee RM, Merlotti L (1992) Comparative effects of pravastatin and lovastatin on nighttime sleep and daytime performance. Clin Cardiol 15(6): 426-32.

[33]. McKinney A, Coyle K, Verster J (2012) Direct comparison of the cognitive effects of acute alcohol with the morning after a normal night's drinking. Hum Psychopharmacol 27(3): 295-304

[34]. Zoethout RW, Delgado WL, Ippel AE, Dahan A, van Gerven JM (2011) Functional biomarkers for the acute effects of alcohol on the central nervous system in healthy volunteers. Br J Clin Pharmacol 71(3): 331-50.

[35]. Harrison EL, Fillmore MT (2011) Alcohol and distraction interact to impair driving performance. Drug Alcohol Depend 117(1): 31-7.

[36]. Ramaekers JG, Theunissen EL, de Brouwer M, Toennes SW, Moeller MR, et al. (2011) Tolerance and cross-tolerance to neurocognitive effects of THC and alcohol in heavy cannabis users. Psychopharmacology (Berl) 214(2): 391-401.

[37]. Wester AE, Verster JC, Volkerts ER, Böcker KB, Kenemans JL (2010) Effects of alcohol on attention orienting and dual-task performance during simulated driving: an event-related potential study. J Psychopharmacol 24(9): 1333-48.

[38]. Loeber S, Duka T, Welzel H, Nakovics H, Heinz A, et al. (2009) Impairment of cognitive abilities and decision making after chronic use of alcohol: the impact of multiple detoxifications. Alcohol 44(4): 372-81.

[39]. Mills KC, Spruill SE, Walker JM, Lamson M (2009) A clinical trial demonstration of a web-based test for alcohol and drug effects. J Stud Alcohol Drugs 70(2): 308-13.

[40]. Saults JS, Cowan N, Sher KJ, Moreno MV (2007) Differential effects of alcohol on working memory: distinguishing multiple processes. Exp Clin Psychopharmacol 15(6): 576-87. 
[41]. Iudice A, Bonanni E, Gelli A, Frittelli C, Iudice G, et al. (2005) Effects of prolonged wakefulness combined with alcohol and hands-free cell phone divided attention tasks on simulated driving. Hum Psychopharmacol 20(2): 125-32.

[42]. Roehrs T, Burduvali E, Bonahoom A, Drake C, Roth T (2003) Ethanol and sleep loss: a "dose" comparison of impairing effects. Sleep 26(8): 981-5.

[43]. Schulte T, Müller-Oehring EM, Strasburger H, Warzel H, Sabel BA. (2001) Acute effects of alcohol on divided and covert attention in men. Psychopharmacology (Berl) 154(1): 61-9

[44]. Fillmore MT, Dixon MJ, Schweizer TA (2000) Differential effects of alcohol on responses to negatively and positively primed stimuli. J Stud Alcohol 61(6): 872-80

[45]. Fillmore MT, Dixon MJ, Schweizer TA (2000) Alcohol affects processing of ignored stimuli in a negative priming paradigm. J Stud Alcohol 61(4): $571-8$

[46]. Koelega HS (1995) Alcohol and vigilance performance: a review. Psychopharmacology (Berl) 118(3): 233-49.

[47]. Stenberg G, Sano M, Rosén I, Ingvar DH (1994) EEG topography of acute ethanol effects in resting and activated normals. J Stud Alcohol 55(6): 64556.

[48]. Lemon J, Chesher G, Fox A, Greeley J, Nabke C (1993) Investigation of the "hangover" effects of an acute dose of alcohol on psychomotor performance. Alcohol Clin Exp Res 17(3): 665-8.

[49]. Roehrs T, Zwyghuizen-Doorenbos A, Knox M, Moskowitz H, Roth T (1992) Sedating effects of ethanol and time of drinking. Alcohol Clin Exp Res 16(3): 553-7.

[50]. Maylor EA, Rabbitt PM, James GH, Kerr SA (1990) Effects of alcohol and extended practice on divided-attention performance. Percept Psychophys 48(5): 445-52.

[51]. Lukas SE, Mendelson JH, Kouri E, Bolduc M, Amass L (1990) Ethanolinduced alterations in EEG alpha activity and apparent source of the auditory P300 evoked response potential. Alcohol 7(5): 471-7.

[52]. Marks DF, MacAvoy MG (1989) Divided attention performance in cannabis users and non-users following alcohol and cannabis separately and in combination. Psychopharmacology (Berl) 99(3): 397-401.

[53]. Moskowitz H, Burns MM, Williams AF (1985) Skills performance at low blood alcohol levels. J Stud Alcohol 46(6): 482-5.

[54]. Mitchell MC (1985) Alcohol-induced impairment of central nervous system function: behavioral skills involved in driving. J Stud Alcohol Suppl 10: 109-16.

[55]. Macavoy MG, Marks DF (1975) Divided attention performance of cannabis users and non-users following cannabis and alcohol. Psychopharmacologia 44(2): 147-52.

[56]. Perez-Reyes M, Hicks RE, Bumberry J, Jeffcoat AR, Cook CE (1988) Interaction between marihuana and ethanol: effects on psychomotor performance. Alcohol Clin Exp Res 12(2): 268-76.

[57]. Mills KC, Bisgrove EZ (1983) Cognitive impairment and perceived risk from alcohol. J Stud Alcohol 44: 26-45.

[58]. Mills KC, Bisgrove EZ (1983) Body sway and divided attention performance under the influence of alcohol: dose-response differences between males and females. Alcohol Clin Exp Res 7(4): 393-97.

[59]. Mills KC, Bisgrove EZ, Hill G, Ballard F, Stepney C (1986) A computer test of actual and simulated BAC impairment. National Institute on Alcohol
Abuse and Alcoholism, Small Business Research Grant, Phase 1, 1 R43 AA 06522-01, London, Ontario 1-17.

[60]. Schwope DM, Bosker WM, Ramaekers JG, Gorelick DA, Huestis MA (2012) Psychomotor performance, subjective and physiological effects and whole blood $\Delta^{9}$-tetrahydrocannabinol concentrations in heavy, chronic cannabis smokers following acute smoked cannabis. J Anal Toxicol 36(6): 405-12.

[61]. Hunault CC, Mensinga TT, Böcker KB, Schipper CM, Kruidenier M, et al. (2009) Cognitive and psychomotor effects in males after smoking a combination of tobacco and cannabis containing up to $69 \mathrm{mg}$ delta-9-tetrahydrocannabinol (THC). Psychopharmacology (Berl) 204(1): 85-94.

[62]. Heishman SJ, Stitzer ML, Yingling JE. (1989) Effects of tetrahydrocannabinol content on marijuana smoking behavior, subjective reports, and performance. Pharmacol Biochem Behav 34(1): 173-9.

[63]. Lamers CT, Ramaekers JG, Muntjewerff ND, Sikkema KL, Samyn N, et al. (2003) Dissociable effects of a single dose of ecstasy (MDMA) on psychomotor skills and attentional performance. J Psychopharmacol 17(4): 379-87.

[64]. Bond A, Lader M (1974) The use of analogue scales in rating subjective feelings. Br J Med Psychol 47: 211-8.

[65]. Carruthers SG, Shoeman DW, Hignite CE, Azarnoff DL (1978) Correlation between plasma diphenhydramine level and sedative and antihistamine effects. Clin Pharmacol Ther 23(4): 375-82.

[66]. McEvoy GK (2013) Diphenhydramine monograph. In: American Hospital Formulary Service. Bethesda: American Society of Hospital Pharmacists $17-$ 20.

[67]. Cohen AF, Posner J, Ashby L, Smith R, Peck AW (1984) A comparison of methods for assessing the sedative effects of diphenhydramine on skills related to car driving. Eur J Clin Pharmacol 27: 477-82.

[68]. Mohs RC, Tinklenberg JR, Roth WT, Kopell BS (1978) Methamphetamine and diphenhydramine effects on the rate of cognitive processing. Psychopharmacology 59: 13-19.

[69]. McEvoy GK (2013) Caffeine monograph. In: American Hospital Formulary Service. Bethesda: American Society of Hospital Pharmacists 2556-9.

[70]. Nieforth KA, Cohen ML (1981) CNS stimulants. In: Principles of Medicinal Chemistry. Foye WO, editor. Philadelphia: Lea \& Febiger 309-12.

[71]. Craig CR (1982) Central nervous stimulants. In: Modern Pharmacology. Boston: Little, Brown Co. 469-72.

[72]. Loke WH, Hinrichs JV, Ghoneim MM (1985) Caffeine and diazepam: separate and combined effects on mood, memory, and psychomotor performance. Psychopharmacology 87: 344-50.

[73]. Greenberg BD, Moore PA, Letz R, Baker EL (1985) Computerized assessment of human neurotoxicity: Sensitivity to nitrous oxide exposure. Clin Pharmacol Ther 38: 656-60.

[74]. Ponds RW, Brouwer WH, van Wolffelaar PC (1988) Age differences in divided attention in a simulated driving task. J Gerontol 43(6): 151-56.

[75]. Kleinknecht RA (1984) Psychomotor skills. Br J Clin Pharmacol 18(Suppl 1): $39 \mathrm{~S}-41 \mathrm{~S}$

[76]. Lundberg PK (1980) Assessment of drugs' side effects: visual analogue scale versus check-list format. Perceptual and Motor Skills 50: 1067-73.

[77]. Palva ES (1985) Gender-related differences in diazepam effects on performance. Med Biol 63(2): 92-95. 